\title{
Hydrocolloid blister plasters vs. standard plasters for foot blisters treatment in real life: a comparative, non- randomised, international, superiority study
}

\author{
Cécile Artus-Arduise ${ }^{1}$, Tracy James ${ }^{1}$, Catherine Monteil ${ }^{1}$, Fiona Hammond ${ }^{2}$, Alison Carr ${ }^{2}$ and Paul Carter ${ }^{1 *}$ \\ ${ }^{1}$ HRA Pharma, 200 avenue de Paris, 92320, Chatillon, France \\ ${ }^{2}$ HAMELL, 1st Floor Dome Building, The Quadrant Richmond, TW9 1DT, United Kingdom
}

\begin{abstract}
Background: Blister plasters are non-invasive and non-sterile dressings composed of a hydrocolloid layer held in place by a polyurethane film and a non-touch foil that provides an ideal healing environment. Their intended use is the protection of blisters providing immediate relief of pain and pressure, cushioning and protection against rubbing. This study was designed to generate additional data to further support some of the main claims of hydrocolloid blister plasters $\left(\mathrm{COMPEED}^{\circledR}\right.$ BLISTER), in a real-life setting.

Methods: The study was a multinational (UK, Spain, Russia), prospective, non-randomised, parallel group comparison of hydrocolloid blister plasters (also called specialist plasters) and standard plasters in real time. Data were collected daily from the time at which participants developed blisters over the following 8-day period.

Results: The cut-off of 50\% of participants experiencing pain relief was set to signify that the hydrocolloid blister plaster provided effective pain relief. This cut-off was statistically significantly exceeded $(55.8 \% \pm 5.1 ; \mathrm{p}<0.05)$ immediately after plaster application, indicating that the specialist plaster provided immediate and sustained pain relief.

Specialist plasters consistently outperformed standard plasters in terms of efficacy (pain relief, time to healing), efficiency (cushioning, adhesion, wear time) and satisfaction. Participants gave hydrocolloid blister plasters significantly higher overall satisfaction ratings than for the standard plasters and nearly all participants would use the specialist plaster again and would recommend them to friends and family. Finally, the hydrocolloid blister plaster was comparable to the standard plaster in terms of safety (solicited and unsolicited adverse events).

Conclusions: The primary objective of this study, to validate the superiority of the specialist plaster in terms of immediate pain relief, was clearly achieved. Further, hydrocolloid blister plasters' superiority in terms of pain relief, adhesion, wear time, cushioning and time to healing were demonstrated. The comparative claim of faster healing, was fully supported by data from participants in each country where it was possible to effectively evaluate healing time.
\end{abstract}

\begin{abstract}
Abbreviations: AE: Adverse Event; CI: Confidence Interval; EP: Evaluable population; GCP: Good Clinical Practice; ICH: International Conference on Harmonization of Technical Requirements for Registration of Pharmaceuticals for Human Use; IEC: Independent Ethics Committee; MEP: Modified Evaluable Population; UK: United Kingdom; HBP: Hydrocolloid Blister Plaster; STP: Standard Blister Plaster
\end{abstract}

\section{Introduction}

Prolonged or unusual exercise frequently leads to friction blisters, thus blisters are most commonly observed in active populations [1,2]. Estimates show, that up to $39 \%$ of marathon runners [3], over $40 \%$ of soldiers in training [4] and over $50 \%$ of hikers [5] are affected by this condition. Although these blisters usually remain a minor skin condition without complications, infections might occur [6], resulting in cellulitis or sepsis and even toxic shock $[7,8]$.

Friction blisters result from mechanical separation of the epidermal cells, followed by accumulation of fluid in the separation due to hydrostatic pressure [1,9] . They frequently develop in areas with a thick, horny layer of skin that adheres firmly to the underlying structures, such as the palms of the hand and the soles of the feet [10]. In addition to the skin characteristics, moisture [11-14] and temperature [13] have been shown to affect blister development.

Most common blister treatments include draining of intact blisters and application of hydrocolloid dressings for roofless blisters $[1,6]$ Blister draining has been shown to relieve discomfort, but bears the risk of infection [6]. The application of hydrocolloid dressings to roofless blisters, has been shown to provide pain relief, allowing a continuation of physical activity $[1,15,16]$. Clinical studies on friction blisters, however, remain scarce, with a focus on military people $[1,7,17]$ or athletes $[2,18-20]$ and the focus of blister prevention, rather than treatment [19].

Hydrocolloid blister plasters such as COMPEED ${ }^{\circ}$ BLISTER are intended to be used by adult consumers for the protection and

${ }^{\star}$ Correspondence to: Paul Carter, HRA Pharma, 200 avenue de Paris, 92320, Chatillon, France, E-mail: c.carter@hra-pharma.com

Key words: blisters, hydrocolloid plasters, effectiveness, pain relief, healing time, cushioning

Received: February 07, 2019; Accepted: February 17, 2020; Published: February 20,2020 

superiority study

cushioning of blisters on the foot and claim to provide instant pain relief, fast healing, protection and cushioning against rubbing and good adhesion. Two clinical studies [21,22] and one post-marketing study [23] currently provide data to support these marketing claims for COMPEED ${ }^{\circledR}$ BLISTER plaster.

The intention of this study was to obtain data from real situations. Therefore, a wide range of consumers at high risk of developing blisters (sportsmen/women shop workers, commuters, tourists) within the next two weeks were recruited for this study. In order to generate data relevant across several markets, participants were recruited in three different countries: the United Kingdom, Spain and Russia.

\section{Methods}

\section{Study Design}

This was a prospective, non-randomised, parallel group comparison of hydrocolloid blister plasters (COMPEED ${ }^{\circledR}$ BLISTER) and standard plasters in real time; data were collected at the point at which participants developed blisters and then daily over an 8-day period as they used the plasters to manage their blisters (data were uploaded daily).

The comparator was chosen on a country-specific basis. The most commonly used standard plaster in each country was used. Elastoplast, Hansaplast and Cosmos were the standard plasters of choice in UK, Spain and Russia respectively.

\section{Study Population}

This study was conducted in consumer populations from September 2018 to December 2018, in three countries: the UK, Spain and Russia. Eligible participants at high risk of developing a foot blister in the next 2 weeks were recruited in each country through public sporting events (national and local running events, charity sports events), sports clubs (running clubs, walking clubs), companies offering specialist walking/ trekking holidays, pharmacies, and advertisements (on Facebook groups for walkers/runners, on websites for shoe retailers).

Eligible participants were male and female adults at high risk of developing a foot blister within the next 2 weeks. They had to have access to a smartphone, tablet or home computer to complete the online questionnaire and to be able and willing to give consent to participate in the 8-day testing. Consumers with a history of diabetes, who already participated in consumer testing for blister plasters in the last month, who were employed by the Research Company (Hamell) or any company that manufactures plasters/blister plasters and who are currently or were within last 6 months employed by a pharmaceutical company, healthcare company, personal care company, market research company, advertising company, marketing company, regulatory or advisory authority, public relations company, media company, radio station or TV company, or as a journalist were excluded from the participation.

\section{Endpoints}

Pain relief: The amount of pain relief experienced after initial application of the blister plasters was measured on a 0-10 graphic rating scale straight after application and at 5, 10 and 30 minutes after initial application.

Time to healing: Time to healing was defined as the time from initial application of the plaster to the time when the participant no longer needed to wear the plaster and considered that the blister had healed
Rating of cushioning and adhesion: Ratings of cushioning and adhesion were assessed using a 6-point descriptive scale. Cushioning was defined as the plaster 'protecting and relieving the pressure on the blister' and adhesion was defined as 'the plaster sticking to the foot'.

Wear time: Mean/median wear time for plasters calculated as the mean/median of the wear times for each application of plaster across all participants.

Satisfaction: Overall satisfaction with the blister plasters was measured on a $0-5$ scale.

\section{Data sources and measurement}

All data were collected in a community setting via an online questionnaire.

All data were entered directly into the online questionnaire by the consumer. The online questionnaire was built in a validated system with built-in data checks to ensure all responses were within valid limits.

\section{Bias}

Allocation of blister plasters to participating consumers was not randomised. However, to ensure the groups of consumers were similar, alternate allocation and supply of specialist plasters and standard plasters was used. It was not possible to blind participants to their plaster allocation; blister plasters were supplied in their commercial packaging.

In the UK and Spain plasters were supplied to participants identified at high risk of developing a blister, but not actually with a blister. This meant that although alternate allocation was employed, the people captured in the comparative groups (hydrocolloid blister plasters vs standard plasters) reflected those who did develop a blister and thus, was not necessarily $1: 1$. In fact there were slightly more consumers in the specialist blister plaster group $(\mathrm{N}=369)$ than the standard plaster group $(\mathrm{N}=308)$ which may have introduced some bias in the analysis but both groups were large enough for the analysis to be considered robust.

In Russia, participants did not receive plasters until a blister had formed. In this circumstance, although the majority (96.8\%) did access their plaster within the first day, a few participants experienced a delay of up to 72 hours, introducing potential bias.

The prospective design of the study, capturing consumer experience data in real time as they used the blister plasters, removed recall bias ensuring that the reported experience was an accurate reflection of the effects of the specialist and standard plasters.

\section{Statistical analyses}

Three analysis populations were defined (Table 1) and analysis was conducted on the modified evaluable population. To be considered evaluable, participants had to fulfil the inclusion/exclusion criteria and complete the pre-application assessments and the post-first application assessments of pain. Participants found not to have satisfied the inclusion/exclusion criteria were excluded from the analysis.

Primary endpoint analysis: The primary endpoint was the proportion of participants who experienced pain relief (defined as reduction of at least 1 point on the $0-10$ graphic rating pain scale from the preapplication pain rating) immediately and within 5, 10 and 30 minutes of first application of COMPEED ${ }^{\circledR}$ BLISTER plaster. 
Artus-Arduise C (2020) Hydrocolloid blister plasters vs. standard plasters for foot blisters treatment in real life: a comparative, non-randomised, international, superiority study

Table 1. Analysis populations

\begin{tabular}{|l|l|l|}
\hline Population & Definition / Criteria & Analyses Evaluated \\
\hline $\begin{array}{l}\text { All Subjects } \\
\text { Screened }\end{array}$ & $\begin{array}{l}\text { All the participants who were screened } \\
\text { were included in the population. }\end{array}$ & Disposition \\
\hline $\begin{array}{l}\text { Evaluable } \\
\text { Population (EP) }\end{array}$ & $\begin{array}{l}\text { Evaluable Population included all } \\
\text { participants that met the inclusion/ } \\
\text { exclusion criteria and completed at least } \\
\text { the day one questionnaire }\end{array}$ & Sensitivity analysis \\
\hline $\begin{array}{l}\text { Modified } \\
\text { Evaluable } \\
\text { Population (MEP) }\end{array}$ & $\begin{array}{l}\text { Modified Evaluable Population (MEP) } \\
\text { included all participants that met the } \\
\text { inclusion/exclusion criteria and completed } \\
\text { the final study questionnaire }\end{array}$ & $\begin{array}{l}\text { Primary and Secondary } \\
\text { response analysis }\end{array}$ \\
\hline
\end{tabular}

The null hypotheses $\left(\mathrm{H}_{01}\right)$ was, that $\leq 50 \%$ of participants experience immediate pain relief at each time point (immediately following application and within 5,10 and 30 minutes of first application). The alternative hypotheses $\left(\mathrm{H}_{\mathrm{al}}\right)$ was, that $>50 \%$ of consumers experience immediate pain relief at each time point (immediately following application and within 5, 10 and 30 minutes of first application).

Secondary endpoints analysis: Secondary endpoints were the comparisons between hydrocolloid blister plasters and standard plasters. The nature of the distribution of quantitative variables was assessed by the Shapiro-Wilk test and differences between specialist and standard plasters were analysed by the Student's t-test (independent samples) or the Mann-Whitney test, depending on the nature of the distribution.

Univariate associations between qualitative variables were assessed by Chi square and or Spearman rank-order correlations. Distribution of blister sizes between the two consumer groups was comparable, thus stratification of analysis was not necessary. Similarly, very few consumers used additional blister healing remedies during the study, so stratification of analysis for these remedies was equally not required.

\section{Results}

\section{Population and demographics}

Among the 1698 screened participants, 744 (44 \%) overall completed the pre-application assessments and the post-first application assessments of pain (evaluable population (EP)), and 678 (40 \%) additionally completed the final questionnaire (modified EP (MEP); Table SI 1). Primary and secondary response analysis was performed on the $678 \mathrm{MEP}$ participants.

Of these 678 MEP participants, 369 were allocated the hydrocolloid blister plaster (HBP), while 309 used the standard plaster (STP; Table 2). Of the $678 \mathrm{MEP}$ participants, 270 were recruited in the UK, 310 in Russia and 98 in Spain. The difference between the numbers of subjects in the two treatment groups was not statistically significant $(\mathrm{p}=0.23$; Table 2).

All participants in the study were adults. They represented both men $(21 \%)$ and women (79\%), as well as all age groups from 18 to over 55 (Table 3), with the largest proportion aged 26-45 years. In relation to age distribution, similar populations of participants were recruited in all countries. In the UK and Russia, however, the participating population was predominantly female ( 88 and $84 \%$, respectively), while the opposite was true in Spain (60\% male; Table 3).

Only a very small proportion of participants used additional blister healing remedies during the study period. These included the application of antiseptic creams and popping the blister. There was no statistically significant difference in the proportion of consumers who used additional remedies between the HBP group (3.8\%) and the STP group ( $8.1 \%$, Chi square $5.73 \mathrm{p}=0.017)$. Similarly, there were no differences between groups in individual countries in the use of additional blister healing remedies (Table SI 9).

\section{Baseline characteristics: Comorbidity and blisters causes}

All participants had friction blisters from shoes (Table 4). Only a very small percentage of participants $(4 \%)$ had pre-existing skin conditions (psoriasis or eczema) that might have affected the adhesion of the plasters or caused reactions to the plasters. Causes for the blisters 'treated' in this study included wearing new shoes (30\%) or wearing shoes that had not been worn for a while (32\%) as well as sporting activities (32\%). A higher percentage of sports related blisters was reported in Spain (68\%).

Table 2. Distribution of MEP participants between treatment groups HBP (hydrocolloid blister plaster) and STP (standard plaster) overall and in individual countries. The difference between the two treatment groups was not statistically significant $(\mathrm{p}=0.23)$

\begin{tabular}{|c|c|c|c|c|}
\hline \multicolumn{5}{|c|}{ Number (\%) of consumers } \\
\hline & Overall & UK (n=270) & Russia (n=310) & Spain (n=98) \\
\hline HBP & $369(54)$ & $153(57)$ & $158(51)$ & $58(59)$ \\
\hline STP & $309(46)$ & $117(43)$ & $152(49)$ & $40(41)$ \\
\hline
\end{tabular}

Table 3. Age and gender demographics of MEP participant population overall and in the different countries. Difference between groups (hydrocolloid plaster $v$ s. standard plaster) was statistically significant: Chi square $61.40, \mathrm{p}<0.0001$.

\begin{tabular}{|c|c|c|c|c|}
\hline $\begin{array}{l}\text { Demographic } \\
\text { characteristic }\end{array}$ & \multicolumn{5}{|c|}{ Number (\%) of consumers } \\
\hline & Overall & UK (n=270) & Russia (n=310) & Spain (n=98) \\
\hline \multicolumn{5}{|c|}{ Age } \\
\hline 18 to 25 years & $123(18.1)$ & $55(20.4)$ & $55(17.7)$ & $13(13.3)$ \\
\hline 26 to 35 years & $205(30.2)$ & $97(35.9)$ & $83(26.8)$ & $25(25.5)$ \\
\hline 36 to 45 years & $210(31.0)$ & $77(28.5)$ & $95(30.6)$ & $38(38.8)$ \\
\hline 46 to 55 years & $105(15.5)$ & $31(11.5)$ & $58(18.7)$ & $16(16.3)$ \\
\hline Over 55 years & $35(5.2)$ & $10(3.7)$ & $19(6.1)$ & $6(6.1)$ \\
\hline \multicolumn{2}{|c|}{ Gender } \\
\hline Male & $141(20.8)$ & $32(11.9)$ & $50(16.1)$ & $59(60.2)$ \\
\hline Female & $537(79.2)$ & $238(88.1)$ & $260(83.9)$ & $39(39.8)$ \\
\hline
\end{tabular}

Table 4. Comorbidity and blister causes. Multiple answers were possible, resulting in a total greater than 678

\begin{tabular}{|c|c|c|c|c|}
\hline & \multicolumn{4}{|c|}{ No. of participants (\%) } \\
\hline & $\begin{array}{l}\text { Overall } \\
(n=678)\end{array}$ & $\begin{array}{c}\text { UK } \\
(\mathbf{n}=\mathbf{2 7 0})\end{array}$ & $\begin{array}{c}\text { Russia } \\
(\mathrm{n}=\mathbf{3 1 0})\end{array}$ & $\begin{array}{r}\text { Spain } \\
(\mathrm{n}=98)\end{array}$ \\
\hline \multicolumn{5}{|l|}{ Comorbidity } \\
\hline Eczema & $\begin{array}{c}19 \\
(2.8)\end{array}$ & $\begin{array}{c}16 \\
(5.9)\end{array}$ & 0 & $\begin{array}{c}3 \\
(3.1)\end{array}$ \\
\hline Psoriasis & $\begin{array}{c}8 \\
(1.2)\end{array}$ & $\begin{array}{c}7 \\
(2.6)\end{array}$ & 0 & $\begin{array}{c}1 \\
(1.0)\end{array}$ \\
\hline \multicolumn{5}{|l|}{ Blister cause } \\
\hline Wearing new shoes & $\begin{array}{c}203 \\
(29.9)\end{array}$ & $\begin{array}{c}74 \\
(27.4)\end{array}$ & $\begin{array}{c}117 \\
(37.7)\end{array}$ & $\begin{array}{c}12 \\
(12.2)\end{array}$ \\
\hline $\begin{array}{l}\text { Walking in shoes you haven't } \\
\text { worn for a while }\end{array}$ & $\begin{array}{c}215 \\
(31.7)\end{array}$ & $\begin{array}{c}79 \\
(29.3)\end{array}$ & $\begin{array}{c}126 \\
(40.6)\end{array}$ & $\begin{array}{c}10 \\
(10.2)\end{array}$ \\
\hline $\begin{array}{l}\text { Wearing shoes you haven't worn } \\
\text { for a while for a special occasion }\end{array}$ & $\begin{array}{c}63 \\
(9.3)\end{array}$ & $\begin{array}{l}37 \\
(13.7)\end{array}$ & $\begin{array}{c}16 \\
(5.2)\end{array}$ & $\begin{array}{c}10 \\
(10.2)\end{array}$ \\
\hline $\begin{array}{l}\text { Wearing your usual shoes but } \\
\text { hotter weather caused them to rub }\end{array}$ & $\begin{array}{c}67 \\
(9.9)\end{array}$ & $\begin{array}{c}27 \\
(10.0)\end{array}$ & $\begin{array}{c}39 \\
(12.6)\end{array}$ & $\begin{array}{c}1 \\
(1.0)\end{array}$ \\
\hline Sporting activities & $\begin{array}{c}217 \\
(32.0)\end{array}$ & $\begin{array}{c}82 \\
(30.4)\end{array}$ & $\begin{array}{c}68 \\
(21.9)\end{array}$ & $\begin{array}{c}67 \\
(68.4)\end{array}$ \\
\hline Other & $\begin{array}{c}28 \\
(4.1)\end{array}$ & $\begin{array}{c}16 \\
(5.9)\end{array}$ & $\begin{array}{c}9 \\
(2.9)\end{array}$ & $\begin{array}{c}3 \\
(3.1)\end{array}$ \\
\hline
\end{tabular}


Artus-Arduise C (2020) Hydrocolloid blister plasters vs. standard plasters for foot blisters treatment in real life: a comparative, non-randomised, international, superiority study

\section{Efficacy}

Pain relief: Reported pain at baseline (immediately before applying the blister plaster) as assessed on the $0-10$ scale (0 (no pain at all) to 10 (the worst pain imaginable)) was moderately high in both the HBP (7/10) and STP (6/10) group, with no statistically significant differences between the groups at baseline ( $\mathrm{p}=0.18$; Table SI 2). Median pain scores were similar across countries with no significant differences between countries $(\mathrm{p}=0.18)$.

The proportion of participants using hydrocolloid blister plasters who experienced pain relief by at least 1 point on the 10 -point pain scale exceeded $50 \%$ immediately after application of the plaster (56\%) and continuously increased from 87 , over 92 up to $96 \%$ over the following 5, 10 and 30 minutes (Table 4). The pain relief at all time points was statistically significant $(\mathrm{p}<0.05)$, leading to the rejection of the null hypothesis.

The results showed a similar pattern in each country with more than 50\% experiencing immediate pain relief, and 52-60, 83-90 and 95$97 \%$ experiencing pain relief at 5, 10 and 30 minutes, respectively. The highest proportion of pain relief at each time point was observed in Russia.

Further, the proportion of participants experiencing immediate pain relief (over first 30 minutes) was significantly higher at all time points for the HBP group than for the STP group ( $\mathrm{p} \leq 0.021$; Figure 1). Similar results were obtained at a country level in the UK, Russia and Spain, with significantly higher proportions of participants using hydrocolloid blister plasters experiencing immediate pain relief after 5 minutes in all countries (Table SI 3).

\section{Cushioning Effect}

Ratings for cushioning of the blister were significantly higher for participants applying specialist plaster than for standard plasters (Figure 2). $73.4 \%$ vs $38.8 \%$, rated the plasters as providing very good or excellent cushioning $(\mathrm{p}<0.0001)$. Similar results were obtained in all countries (Table SI 4 ).

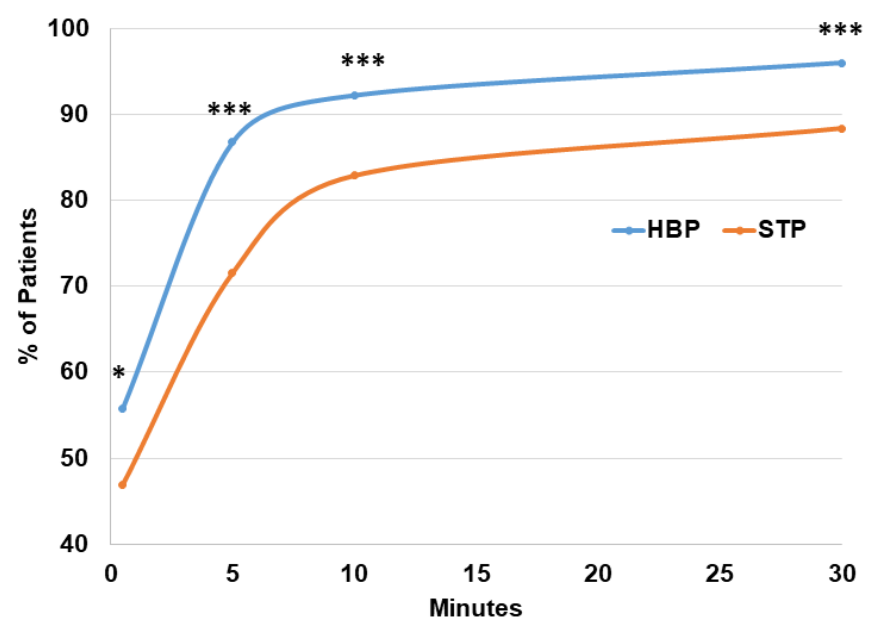

Figure 1. Proportion of MEP subjects with pain relief

Percentages of patients experiencing pain relief ( $\geq 1$ point reduction on Pain scale) immediately after application of the hydrocolloid blister plasters (HBP) or standard (STP) plasters, at 5, 10 and 30 minutes. Pain relief was significantly higher in the HBP group than in the STP group at all time points $(* \mathrm{p}<0.05, * * * \mathrm{p}<0.0001)$.

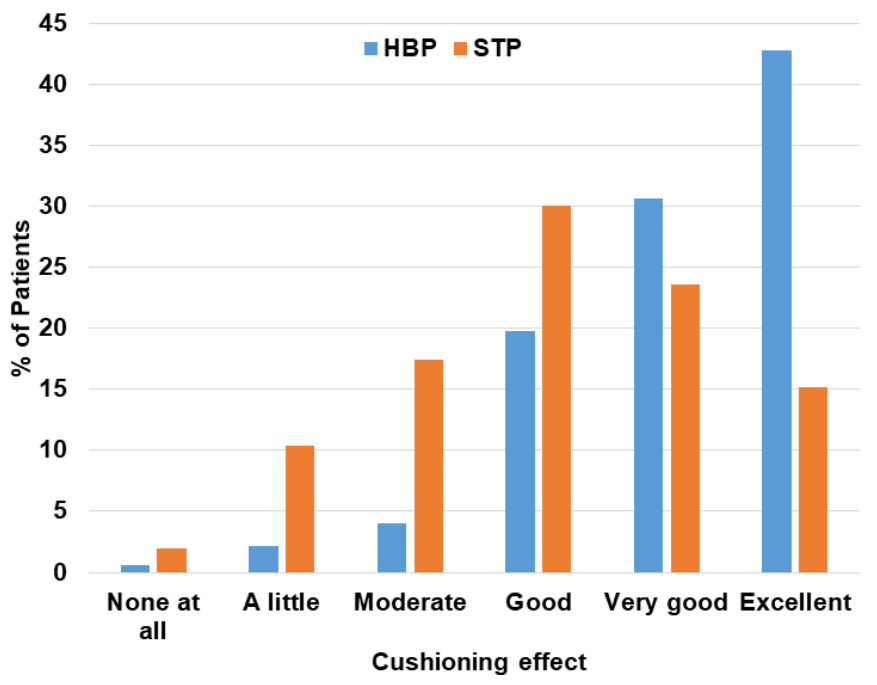

Figure 2. Patients-reported cushioning effect

Cushioning effect between hydrocolloid blister plasters (HBP) and standard (STP) plasters Difference between groups (HBP and STP) was statistically significant: Chi square 108.38, $\mathrm{p}<0.0001$.

\section{Adhesion and wear time}

Hydrocolloid blister plasters users gave significantly higher ratings for adhesion than users of standard plasters (Figure 3). $89.5 \%$ vs $67.7 \%$ of participants rated the plasters as sticking to their foot very well or perfectly $(\mathrm{p}<0.0001)$. Similar results were obtained at a country level in the UK, Russia and Spain (Table SI 5).

Although both specialist and standard plasters were changed on multiple occasions throughout the study period, standard plasters were changed much more frequently (a total of 1041 changes over the study period) than hydrocolloid blister plasters (a total of 765 changes), with a significantly longer median wear time for hydrocolloid blister plasters than standard plasters ( 2 vs 1 day, $\mathrm{p}<0.0001)$. (Table SI 6 ).

\section{Time to healing}

No difference between the proportion of healed blisters was observed at 8 days between specialist and standard plasters ( 75 vs. $74 \%$ ) and no statistical difference was found between countries (Table SI 7). This probably reflected the natural course of blister healing. Since there was an equal distribution of size of blister at baseline between the groups of participants using hydroclloid blister plasters and standard plasters (Table SI 8), there was no requirement to stratify analysis by size of blister.

The time of healing was the only endpoint in the study where HBP was not statistically significantly different from standard plasters across all countries. Indeed, The Cox regression analysis showed that blisters of participants using HBP healed significantly faster than those of subject using standard plasters (hazard ratio 0.667, $\mathrm{p}=0.011$ ) (Table 6). It is important to point out that this analysis was performed on data from UK and Spain only since a high proportion of Russian participants removed their plasters daily as a matter of course. In addition, the cox regression analysis revealed that changing the plasters less frequently contributed to faster healing (hazard ratio 0.608, $\mathrm{p}<0.0001$ ) (Table 6). Since faster healing was observed for participants who changed their plasters less frequently in Spain \& the UK $(\mathrm{p}<0.0001)$ compared to Russia, it is possible that changing hydrocolloid blister plasters this regularly prevented the advantages afforded by the dressing from playing a part in the healing process of the Russian subjects. 
Artus-Arduise C (2020) Hydrocolloid blister plasters vs. standard plasters for foot blisters treatment in real life: a comparative, non-randomised, international, superiority study

\section{Satisfaction}

Subjects using specialist plasters gave significantly higher ratings for overall satisfaction than participants using standard plasters. $94 \%$ of participants using hydrocolloid blister plasters gave high satisfaction ratings ( 4 or 5 on a 0 (not at all satisfied) to 5 (extremely satisfied) scale) while significantly fewer participants using standard plasters gave equally high ratings (75\%; Chi square 72.93, $<<0.0001$; Figure 4). Similar results were obtained at a country level with the difference being significant in all countries (Table SI 10- Table SI 12).

Further, almost all (99\% and 98\%, respectively) participants using HBP said that they would use such plasters again or recommend it to their family and friends (Table 7 ). These ratings were significantly higher than for the group of participants using standard plasters $(86 \%$ and $84 \%$, respectively).

\section{Safety}

The numbers of solicited adverse events and quality complaints reported were very low for both specialist and standard plasters and there were no significant differences between the two groups (Table

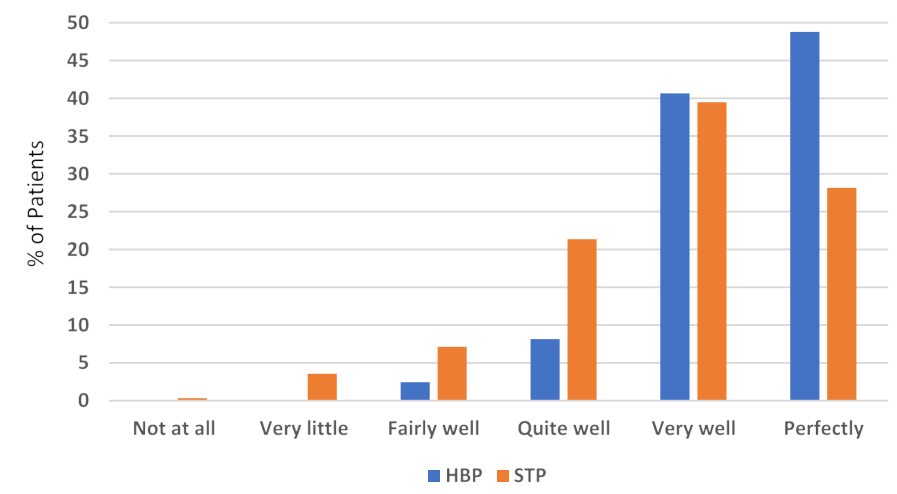

Figure 3. Patient-reported plaster adhesion

Difference in adhesion between hydrocolloid blister plasters and standard plasters. Difference between groups (hydrocolloid plaster vs. standard plaster) was statistically significant: Chi square $61.40, \mathrm{p}<0.0001$.

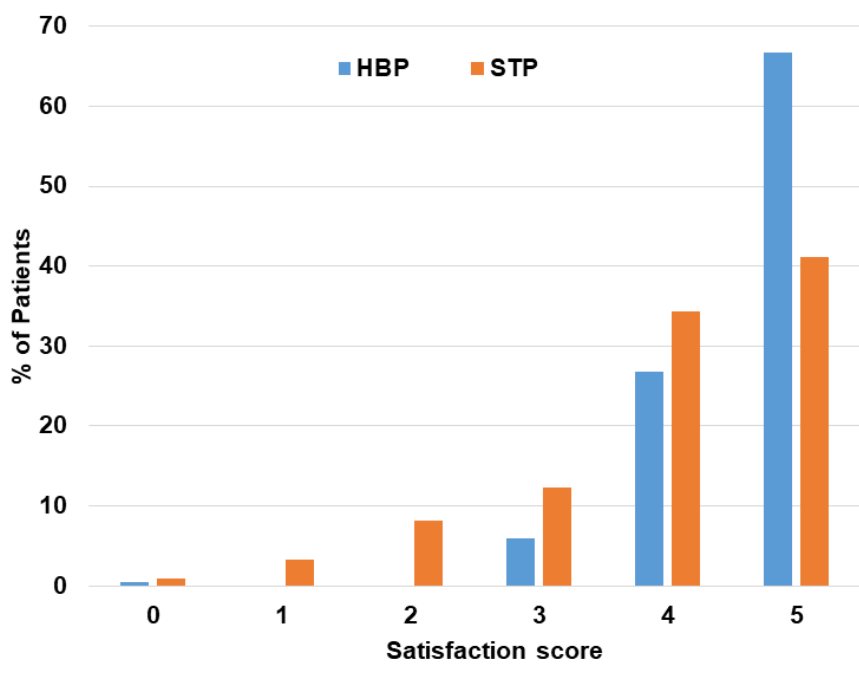

Figure 4. Overall satisfaction ratings

Overall satisfaction scores between hydrocolloid blister plasters (HBP) and standard plasters (STP) on a scale from 0 (not satisfied) to 5 (very satisfied). Difference between groups (HBP and STP) were statistically significant: Chi square 72.93, $\mathrm{p}<0.0001$.
Table 5. Pain relief ( $\geq 1$ point reduction on pain scale) by hydrocolloid blister plaster over the first 30 minutes

\begin{tabular}{|c|c|c|c|c|c|c|}
\hline & \multicolumn{6}{|c|}{ No. of participants (\%) } \\
\hline & \multicolumn{3}{|c|}{$\begin{array}{l}\text { Overall } \\
(n=369)\end{array}$} & \multirow{2}{*}{$\underset{(n=153)}{\text { UK }}$} & \multirow{2}{*}{$\begin{array}{c}\text { Russia } \\
(n=158)\end{array}$} & \multirow{2}{*}{$\begin{array}{c}\text { Spain } \\
(\mathrm{n}=58)\end{array}$} \\
\hline & Number & $95 \%$ CI & \begin{tabular}{|c|} 
Statistical \\
significance
\end{tabular} & & & \\
\hline Immediately & $\begin{array}{c}206 \\
(55.8)\end{array}$ & 50.7 to 60.9 & $\mathrm{p}<0.05$ & $\begin{array}{c}80 \\
(52.3)\end{array}$ & $\begin{array}{c}95 \\
(60.1)\end{array}$ & $\begin{array}{c}31 \\
(53.4)\end{array}$ \\
\hline 5 minutes & $\begin{array}{c}320 \\
(86.7)\end{array}$ & 83.2 to 90.2 & $\mathrm{p}<0.0001$ & $\begin{array}{c}130 \\
(85.0)\end{array}$ & $\begin{array}{c}142 \\
(89.9)\end{array}$ & $\begin{array}{c}48 \\
(82.8)\end{array}$ \\
\hline 10 minutes & $\begin{array}{c}340 \\
(92.1)\end{array}$ & 89.3 to 94.9 & $\mathrm{p}<0.0001$ & $\begin{array}{c}139 \\
(90.8)\end{array}$ & $\begin{array}{c}147 \\
(93.0)\end{array}$ & $\begin{array}{c}54 \\
(93.1)\end{array}$ \\
\hline 30 minutes & $\begin{array}{c}354 \\
(95.9)\end{array}$ & 93.9 to 97.9 & $\mathrm{p}<0.0001$ & $\begin{array}{c}148 \\
(96.7)\end{array}$ & $\begin{array}{c}150 \\
(94.9)\end{array}$ & $\begin{array}{c}56 \\
(96.6)\end{array}$ \\
\hline
\end{tabular}

Table 6. Cox regression analysis on time of healing between specialist and standard plasters (UK and Spain). Hazard ratios represent the likelihood to have a wound healed the next day. A hazard ratio $<1$ means that healing time is reduced (specialist vs. standard, less frequent plaster changing vs. more frequent changing, respectively)

\begin{tabular}{|c|c|c|c|c|c|}
\hline & $\begin{array}{c}\text { Standard } \\
\text { Error }\end{array}$ & p value & Hazard ratio & \multicolumn{2}{|c|}{$\mathbf{9 5 . 0 \%}$ CI for hazard ratio } \\
\cline { 5 - 6 } & 0.159 & 0.011 & 0.667 & 0.489 & 0.910 \\
\hline Plaster used & $0.60 r$ & Upper \\
\hline $\begin{array}{c}\text { Frequency of } \\
\text { changing }\end{array}$ & 0.073 & $<0.001$ & 0.608 & 0.527 & 0.701 \\
\hline
\end{tabular}

Table 7. The difference in likelihood to purchase and recommend the plaster between consumers using COMPEED ${ }^{\circledR}$ BLISTER (HBP) and those using standard plasters (STP)

\begin{tabular}{|c|c|c|c|c|c|}
\hline & & $\begin{array}{l}\text { Number }(\%) \\
\text { HBP } \\
(\mathrm{n}=369)\end{array}$ & $\begin{array}{l}\text { Number }(\%) \\
\text { STP } \\
(\mathrm{n}=309)\end{array}$ & Chi square & $\begin{array}{l}\text { Significance } \\
\text { (p) }\end{array}$ \\
\hline \multirow{2}{*}{$\begin{array}{l}\text { Would you purchase } \\
\text { this plaster again? }\end{array}$} & Yes & 365 (98.9) & $267(86.4)$ & \multirow{2}{*}{41.60} & \multirow{2}{*}{$<0.0001$} \\
\hline & No & $4(1.1)$ & $42(13.6)$ & & \\
\hline \multirow{2}{*}{$\begin{array}{l}\text { Would you } \\
\text { recommend this } \\
\text { plaster to family and } \\
\text { friends? }\end{array}$} & Yes & $362(98.1)$ & $258(83.5)$ & \multirow[b]{2}{*}{45.87} & \multirow[b]{2}{*}{$<0.0001$} \\
\hline & No & $7(1.9)$ & $51(16.5)$ & & \\
\hline
\end{tabular}

SI 13). This was also the case within individual countries. The most commonly named adverse event for hydrocolloid blister plaster was the removal of skin (1.6\%), followed by a lack of healing or increase of size of the blister $(0.8 \%)$. The latter was the most common solicited adverse event for the standard plaster (1.6\%), followed by skin irritation or rashes $(1.0 \%)$.

Similarly, the numbers of unsolicited adverse events and quality complaints were also low for hydrocolloid blister plasters (Table SI 14). Overall, more unsolicited quality complaints and adverse events were reported for standard plasters $(8.1 \%)$ than for specialist plasters (5.7\%). One serious unsolicited adverse event, namely death from a ruptured cerebral artery aneurysm resulting in a subarachnoid haemorrhage, was reported for a hydrocolloid blister plaster subject in the UK, but was considered unrelated to the blister treatment. The event occurred on the third day of treatment and the subject had a long history of migraines and high blood pressure.

\section{Discussion}

The aim of this study was to demonstrate immediate pain relief by hydrocolloid blister plasters (COMPEED ${ }^{\circ}$ BLISTER), as well as to evaluate their efficacy compared to standard plasters in terms of pain relief, adhesion, wear time, cushioning and time to healing. Major outcomes of this study were the demonstration of (1) immediate pain relief by the application of hydrocolloid blister plasters, as well as (2) significantly better pain relief by specialist plasters compared 

superiority study

to standard plasters, and significantly (3) better adhesion, (4) better cushioning, (5) longer wear time, and (6) faster healing. The only comparative claim that could not be fully supported by the data across all countries was faster healing, which was significantly better in Spain \& the UK, but not in Russia. These results might, however, have been confounded by patterns of wear time, since significantly more Russian customers changed their plasters daily, even without necessity and a low changing frequency was shown to contribute to faster healing.

The participant satisfaction was evaluated and showed that the overall satisfaction level was significantly higher for specialist plasters than for standard plasters, with almost all participants in the former group stating that they would use such plasters again and recommend them to family and friends. In terms of safety, evaluated on the basis of reported adverse events, no significant differences between products was observed, with very low numbers of reports.

One limitation of this study is that the participants could not be blinded to their plaster allocation and that the allocation of specialist and standard plasters was not randomised, allowing the outcome to possibly be biased. To minimize this bias, alternate allocation between hydrocolloid blister plasters and standard plasters was used and assessment of the distribution of key potential confounders (blister size and use of additional blister healing remedies) was performed.

Another limitation of the study is the potential bias introduced by the distribution strategy. In the UK and Spain, the plasters were handed out to consumer with the potential to develop blister, rather than those who already had them. Since the distribution between those customers who actually developed blisters could not be foreseen, the sizes of the blister plaster groups were not equal, with less consumers in the standard plaster group. This unequal distribution between the two groups (369 vs. 308) might have introduced some bias in the analysis, but both groups were large enough for the analysis to be considered robust. In Russia, on the other hand, customers only received plasters if a blister had already developed, thereby avoiding the unequal distribution between the two plaster groups, but introducing a potential bias due to the lag phase (within $24 \mathrm{~h}$ for $>96 \%$, up to $72 \mathrm{~h}$ for $<4 \%$ ) between blister development and plaster application.

Despite the above mentioned limitations, the study has a high practical relevance due to its prospective design, the broad group of participants and its geographic location. Studies for which results are reported retrospectively have been shown to report lower blister incidence rates [24,25], thus the prospective design of the study, capturing subject experience data in real time by using an app to enter results, ensured that the data are an accurate reflection of the effects experienced and removed any recall bias. Further, as most previous clinical studies on friction blisters focus on military people $[1,7,17]$ or athletes [2,18-20], the broad inclusion criteria in this study ensured that the results can be generalized across age groups, gender, as well as level and type of activity causing blisters. Finally, the study was conducted in three countries. Since environmental factors, such as moisture [11-14] and temperature [13] have been shown to affect blister formation, countries with distinct climates were selected in order to ensure generalizability of the data to most regions.

\section{Conclusion}

The study showed that blister sufferers achieved immediate pain relief by the application of hydrocolloid blister plasters (COMPEED ${ }^{\circ}$
BLISTER) and that this pain relief was significantly better than for standard plasters. Furthermore, hydrocolloid blister plasters' performance was better in terms of adhesion, cushioning, wear time and healing time. The satisfaction level of participants having used hydrocolloid blister plasters was significantly higher than for those having used standard plasters. Due to its prospective design, the choice of population and geographic location, the results should be relevant across a wide range of markets and consumers.

\section{Acknowledgements}

The authors thank Thibaut de Sablet of Clinact, France for providing medical writing support/editorial support which was funded by HRA, France in accordance with Good Publication Practice (GPP3) guidelines.

\section{Funding}

Funding for this research has been provided by HRA Pharma.

\section{Availability of data and materials}

All datasets analysed for the current study may be made available from the corresponding author on reasonable request.

\section{Authors' contributions}

CAA and PC designed the study and validated the results; TJ validated the results; $\mathrm{CM}$ designed the study; $\mathrm{FH}$ and $\mathrm{AC}$ conducted the study, analysed the results and wrote the study report.

\section{Ethics Declarations}

\section{Ethics approval and consent to participate}

This trial has been approved on the 9th of October 2018 by the Spanish Independent Ethics committee (Fundación Jiménez Díaz Clinical Research Ethics Committee). IEC approval was not sought for the other countries (UK and Russia) as it is not required for post market studies.

Prior to participation, written informed consent was obtained from all subjects from each country. The study was conducted in compliance with the principles of the Declarations of Helsinki and was in compliance with the Good Clinical Practice (ICH-GCP).

\section{Competing interests}

CAA, TJ, CM and PC are respectively, Head of Clinical Operations, Global Category Lead, Clinical project coordinator and Chief Scientific Officer at HRA Pharma France and FH and AC received fees from HRA Pharma for managing the study and writing the study report.

\section{References}

1. Knapik JJ, Reynolds KL, Duplantis KL (1995) Friction Blisters: Pathophysiology, Prevention and Treatmenta. Sports Med 20: 136-147.

2. Brennan FH (2002) Managing Blisters in Competitive Athletes. Curr Sports Med Rep 1: 319-322.

3. Mailler-Savage EA, Adams BB. Skin manifestations of running. J Am Acad Dermatol 55: 290-301.

4. Patterson HS, Woolley TW, Lednar WM (1994) Foot blister risk factors in an ROTC summer camp population. Mil Med 159: 130-135. [Crossref]

5. Twombly SE, Schussman LC (1995) Gender differences in injury and illness rates on wilderness backpacking trips. Wilderness \& Environmental Medicine 6: 363-376.

6. Cortese CTA, Sulzberger MB (1968) Treatment of Friction Blisters. An experimental study. Arch Dermatol 97: 717-721. 
Artus-Arduise C (2020) Hydrocolloid blister plasters vs. standard plasters for foot blisters treatment in real life: a comparative, non-randomised, international, superiority study

7. Hoeffler DF (1975) Friction Blisters and Cellulitis in a Navy Recruit Population. Mil Med 140: 333-337.

8. Taylor CM, Riordan FA, Graham C (2006) New football boots and toxic shock syndrome. BMJ 332: 1376-1378. [Crossref]

9. NAYLOR PF (1955) Experimental friction blisters. Br J Dermatol 67: 327-342. [Crossref]

10. Sulzberger MB, Cortese TA, Fishman L (1966) Studies on Blisters Produced by Friction. Journal of Investigative Dermatology 47: 456-465.

11. Highley KR, Coomey M, DenBeste M, Wolfram LJ (1977) Frictional properties of skin. J Invest Dermatol 69: 303-305. [Crossref]

12. Nacht, Sergio, Close, Jo-Ann, Yeung, David, et al. (1981) Skin friction coefficient changes induced by skin hydration and emollient application and correlation with perceived skin feel. J Soc Cosmet Chem 32: 55-65.

13. Akers WA (1977) Sulzberger on friction blistering. Int J Dermatol 16: 369-372. [Crossref]

14. Tomlinson SE, Lewis R, Liu X (2011) Understanding the Friction Mechanisms Between the Human Finger and Flat Contacting Surfaces in Moist Conditions. Tribol Lett 41: 283-294.

15. Alvarez OM, Mertz PM, Eaglstein WH (1983) The effect of occlusive dressings on collagen synthesis and re-epithelialization in superficial wounds. J Surg Res 35: 142-148.
16. Hedman LA (1988) Effect of a Hydrocolloid Dressing on the Pain Level from Abrasions on the Feet during Intensive Marching. Military Medicine 153: 188-190.

17. Van Tiggelen D, Wickes S, Coorevits P, Dumalin M, Witvrouw E (2009) Sock systems to prevent foot blisters and the impact on overuse injuries of the knee joint. Mil Med 174: 183-189. [Crossref]

18. Lipman GS, Sharp LJ, Christensen M (2016) Paper Tape Prevents Foot Blisters: A Randomized Prevention Trial Assessing Paper Tape in Endurance Distances II (PreTAPED II). Clin J Sport Med 26: 362-368.

19. Janssen L, Allard NAE, Haaf DSM ten (2018) First-Aid Treatment for Friction Blisters "Walking Into the Right Direction?" Clinical Journal of Sport Medicine 28: 37-42.

20. Tasron DN, Thurston TJ, Carré MJ (2015) Frictional Behaviour of Running Sock Textiles Against Plantar Skin. Procedia Engineering 112: 110-115.

21. Karlsmark (2000) Un published clinical study: Protocol 7151071.TK1.

22. Steinkraus (2008) Unpublished clinical study: Protocol HCOWDH4002.

23. Unpublished post-marketing study (2009) EMEA Topical Health Care.

24. Crouse BJ, Josephs D (1993) Health care needs of Appalachian trail hikers. J Fam Pract 36: 521-525. [Crossref]

25. Polliack AA, Scheinberg S (2006) A New Technology for Reducing Shear and Friction Forces on the Skin: Implications for Blister Care in the Wilderness Setting. Wilderness Environ Med 17: 109-119.

Copyright: (C2020 Artus-Arduise C. This is an open-access article distributed under the terms of the Creative Commons Attribution License, which permits unrestricted use, distribution, and reproduction in any medium, provided the original author and source are credited. 